\title{
The Effect of Pretreatment with Chemotherapeutic Drugs on the Susceptibility to Lymphokine Activated CD8+ T Lymphocyte- Mediated Cytotoxicity in CMK Leukemia Cells
}

\author{
Bülent Özgönenel", Öner Özdemir, Melike Özgönenel, Ronald Thomas, Steven Buck and \\ Süreyya Savaşan
}

\author{
Division of Hematology/Oncology, Children's Hospital of Michigan, Wayne State University, Detroit, Michigan, \\ USA
}

\begin{abstract}
Objectives: Certain tumor cells pretreated with chemotherapeutic drugs become more susceptible to death by apoptosis induced by killer cells of the immune system. We examined the CD8+ cytotoxic T lymphocyte (CTL)-mediated cytotoxicity in myeloid leukemia cell lines pretreated with chemotherapeutic drugs.
\end{abstract}

Methods: Peripheral blood mononuclear cells were expanded in vitro in the presence of phytohemagglutinin- $P$ interleukins-2 and -15 . CD3+ CD8+ cells representing the CTLs were isolated using magnetic immunoselection and used in immune cytotoxicity experiments against K562 and CMK leukemia cells, pretreated with two different concentrations of cytarabine and etoposide.

Results: In CMK cells pretreated with etoposide at $2 \mu \mathrm{M}$ and $20 \mu \mathrm{M}$ concentrations, the mean cell-mediated immune cytotoxicity rose to $21.4 \pm 12.9 \%(p=0.09)$ and $23.4 \pm 12.6 \%(p=0.046)$, respectively, when compared to the control value of $6.6 \pm 3.8 \%$. In CMK cells pretreated with cytarabine at $1 \mu \mathrm{M}$ and $10 \mu \mathrm{M}$ concentrations, the mean immune cytotoxicity rose to $14.3 \pm 11.2 \%$ and $22.6 \pm 15.2 \%$, respectively, compared to the control value of $8.7 \pm 6.3 \%$, although these results did not reach statistical significance. However, a similar increase in CTL-mediated immune cytotoxicity was not observed against drug-treated K562 cells.

Conclusion: This study suggests that pretreatment with chemotherapeutic drugs can render CMK leukemia cells more susceptible to immune attack by activated CTLs. Further studies are needed to explore this phenomenon, to establish an immune-enhancing effect of pretreatment with chemotherapy in the treatment of leukemia.

Keywords: Leukemia, cytotoxic T lymphocytes, chemotherapy, apoptosis.

\section{INTRODUCTION}

The presence of an effective anti-leukemic immune response may be important in the eradication of leukemia. Two therapeutic modalities used in the treatment of leukemia, allogeneic hematopoietic stem cell transplantation (HSCT) and donor lymphocyte infusions (DLIs), operate through an allogeneic cellmediated immune reaction, termed the graft-versusleukemia (GVL) reaction [1, 2]. The effector cells involved in the GVL reaction include the natural killer (NK) cells and the cytotoxic T lymphocytes (CTLs). The high rate of relapse following T cell-depleted HSCT for hematologic malignancies [3] and reversal of relapse following DLI $[4,5]$ constitute evidence for the important role CTLs play in the mediation of the GVL. It can be speculated that enhancing the immune capabilities of CTLs may help reduce radiation and chemotherapy doses but still achieve cure from leukemia. This can be achieved by priming donor's T cells with tumoral antigens prior to HSCT and thereby producing clones of donor cytotoxic effector cells

*Address correspondence to this author at the Hematology/Oncology, Children's Hospital of Michigan, 3901 Beaubien Blvd., Detroit, MI, 48201, USA; Tel: 313-7455515; Fax: 313-7455237; E-mail: bulentozgonenel@yahoo.com specifically targeting tumoral tissue; however, this approach is cumbersome, time-consuming and not always feasible in the clinical setting. Fortunately, both CTLs and NK cells can be activated and expanded in vitro with interleukin (IL)-2 stimulation without priming with tumoral antigens. Such cells are called lymphokine-activated killer (LAK) cells $[6,7]$.

Effector/cytotoxic cells of the immune system kill tumor cells through activation of apoptosis, or programmed cell death. The two major molecular mechanisms involved in the induction of apoptosis in the target cells include the granule exocytosis (perforin/granzyme pathway), and death ligand/death receptor interaction. The death receptors that transmit apoptotic signals into the target cell are membranespanning proteins that belong to the tumor necrosis factor (TNF) receptor family of molecules, and include the Fas, TNF receptor 1 , and receptors for the TNF receptor apoptosis inducing ligand (TRAIL). The corresponding ligands expressed by the effector/cytotoxic cells include the Fas ligand, TNF- $\alpha$, and TRAIL, respectively [8-10].

One of the ways tumor cells evade immune surveillance is by blocking apoptotic signals that could 
be delivered by the effector cells of the immune system. This could be either through down-regulation of death receptors on the cell surface or by disabling intracellular downstream pathways of apoptosis. Chemotherapeutic drugs can reverse this immune evasion by either up-regulating the surface death receptors or salvaging the downstream pathways, ultimately re-establishing a pro-apoptotic state in the tumor cell [11, 12]. As an example, in esophageal cancer cell lines, cisplatin induces the expression of Fas. Through Fas/Fas ligand interaction, LAK cells thus exert an augmented cytotoxicity against esophageal cancer cells pretreated with cisplatin [13]. Similarly, leukemia cells exposed to chemotherapeutic drugs become more sensitive to the anti-leukemic activity of soluble TRAIL [14]. Anti-leukemia drug homoharringtonine sensitizes human colorectal carcinoma cells to TRAIL-induced apoptosis [15]. The synergistic effects of combining cell-mediated immune therapy with pretreatment of tumor cells have been shown in several tumor cell lines, using different chemotherapeutic drugs [16-31].

In this study we have examined immune cytotoxicity by unprimed lymphokine-activated peripheral blood CD8+ T lymphocytes against myeloid leukemia cell lines that were pretreated with chemotherapeutic agents. We were able to demonstrate that pretreatment with chemotherapeutic agents could render at least one leukemic cell line more vulnerable to CTL-mediated immune killing.

\section{MATERIALS AND METHODS}

\section{Generation of CD8+ -LAK Cells}

Peripheral blood samples were collected from 6 healthy volunteers in accordance with the protocols approved by the Wayne State University Human Investigations Committee and the Institutional Review Board. Peripheral blood mononuclear cells were isolated after centrifugation of fresh blood collected from 6 healthy volunteer donors on Ficoll Histopaque1077 and were cultured for six days at a concentration of $1 \times 10^{6}$ cells $/ \mathrm{ml}$ in RPMI 1640 medium supplemented with $10 \%$ fetal bovine serum, $2 \mathrm{mM}$ glutamine, $50 \mu \mathrm{g} / \mathrm{ml}$ gentamycin in the presence of IL-2 $(100 \mathrm{U} / \mathrm{ml}), \mathrm{IL}-15(10 \mathrm{ng} / \mathrm{ml})$, and phytohemagglutinin-P $(5 \mu \mathrm{g} / \mathrm{mL})[32,33]$.

\section{Isolation of CD8+ -CTLs}

On the $6^{\text {th }}$ day of incubation, CD3+CD8+ LAK cells were purified using immunomagnetic negative selection
(Miltenyi Biotec, Gladbach, Germany), according to the manufacturer's protocol for CD8+ T Cell Isolation Kit II. Briefly, LAK cells were magnetically labeled with a cocktail of biotin-conjugated antibodies against CD4, CD16, CD19, CD36, CD56, glycophorin A, CD123, and TCR $\gamma / \delta$, which were subsequently labeled with antibiotin antibody-coupled magnetic cell sorter (MACS) microbeads for depletion. Immobilization of the magnetically labeled cells on a depletion column isolated the CD3+ CD8+ cells. The separated cells were cultured in RPMI 1640 medium supplemented with $10 \%$ fetal bovine serum and antibiotics as described above. These cells were used in the coincubation assays on days 1-4 of separation.

\section{Target Cells}

Two myeloid leukemia cell lines, K562 and CMK, served as the target cells. K562 cells, originally derived from the erythroleukemia blast crisis of a patient with chronic myeloid leukemia [34], were obtained from ATCC (Manassas, VA). CMK cells, established from an individual with Down's syndrome suffering from acute megakaryoblastic leukemia [35], were obtained from German Collection of Microorganisms and Cell Cultures (Brunschweig, Germany). Cells were maintained in RPMI 1640 culture media, supplemented with $10 \%$ FBS. Target cells were placed in three separate wells for a twelve-hour overnight incubation with drugs (cytarabine $1 \mu \mathrm{M}$ and $10 \mu \mathrm{M}$ concentrations; or etoposide $2 \mu \mathrm{M}$ and $20 \mu \mathrm{M}$ concentrations) or without drugs (controls). We determined the dose of each chemotherapeutic drug based on our earlier experiments with these agents [33].

\section{Flow Cytometric Cell-mediated Cytotoxicity Assay}

At the end of the incubation with drugs, effector and target cells were co-incubated at a 4:1 effector/target ratio in $12 \times 75 \mathrm{~mm}(5 \mathrm{~mL})$ round bottom polystyrene tubes (Falcon, Becton-Dickinson, Franklin Lakes, NJ) at $37^{\circ} \mathrm{C}$ in $5 \% \mathrm{CO}_{2}$ for 2 hours following an initial centrifugation at $115 \mathrm{~g}$ for 5 minutes. We decided to use 2 hour co-incubation time in this study since our earlier experiments showed good correlation between 2 hour and 4 hour killings [36]. Following co-incubation, 5 $\mu \mathrm{l}$ of mouse anti-human PE-conjugated monoclonal antibody to CD33 (Immunotech, Inc., Westbrook, ME) was added into the cell suspension to label target cells. $10 \mu \mathrm{l}$ of FITC-conjugated annexin $\mathrm{V}(\mathrm{annV})$ and propidium iodide $(\mathrm{PI})$ and $50 \mu \mathrm{l}$ of Annexin Buffer (TACS $^{\text {TM }}$ AnnexinV-FITC; R\&D Systems, Minneapolis, $\mathrm{MN}$ ) were also added into the cell suspension to label 
Control
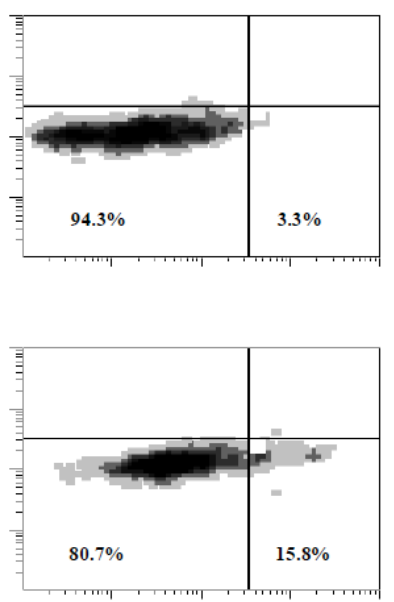

Etoposide $2 \mu \mathrm{M}$
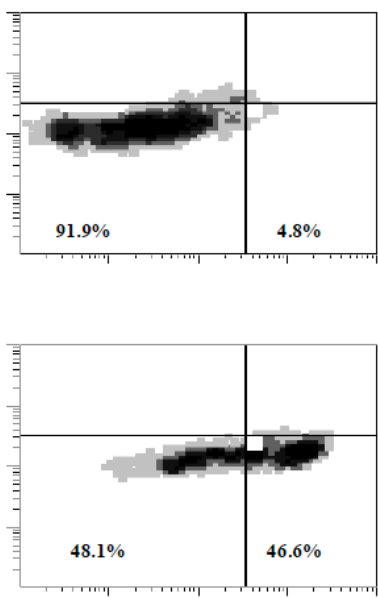

Etoposide 20 $\mu \mathrm{M}$
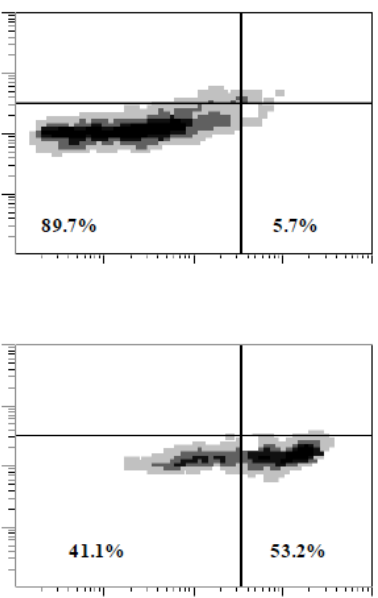

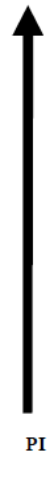

AnnexinV

A

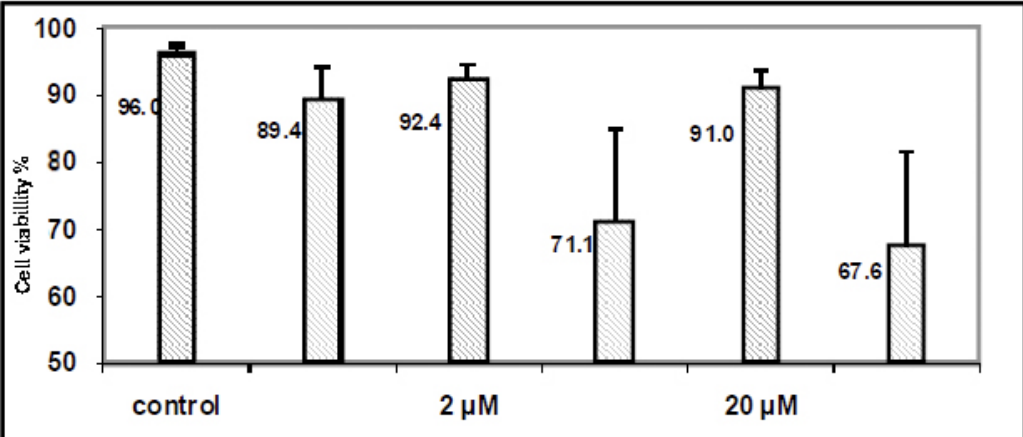

B

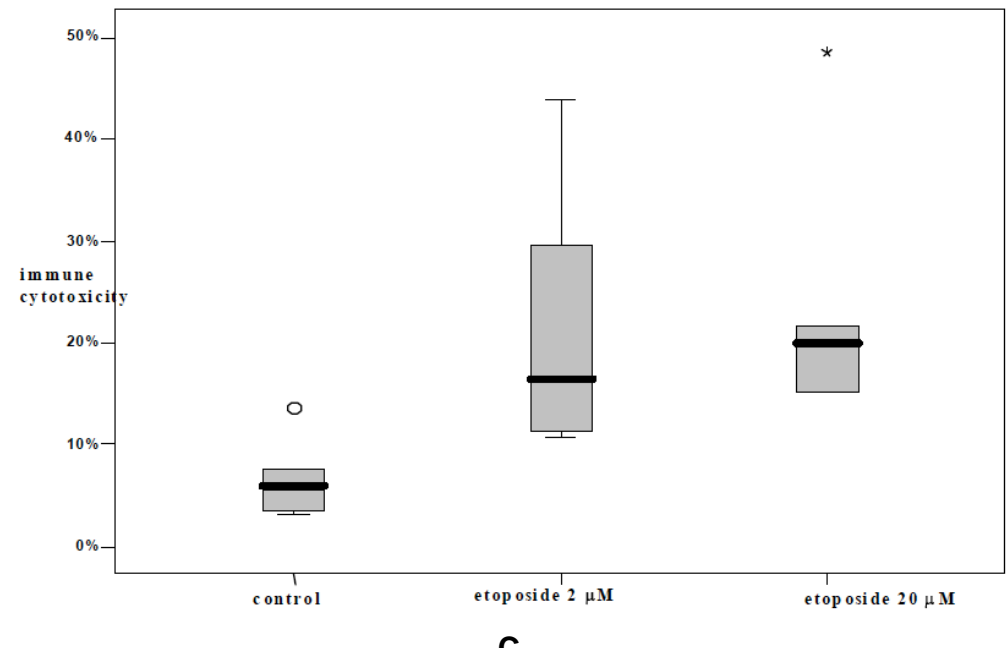

C

Figure 1: Pretreatment with etoposide increases susceptibility of CMK cells to CTL-mediated cytotoxicity. (A) Etoposide pretreated cells became apoptotic, showing increased AnnV binding, as seen in histograms from a representative experiment where CD8+ CTLs were co-incubated with CMK cells pretreated with etoposide. The upper panel displays baseline and the lower panel displays co-incubation histograms. In this sample, baseline cell viability decreased from $94.3 \%$ to $80.7 \%$ following co-incubation with CTLs, producing an immune cytotoxicity value of $13.6 \%$. In cells pretreated with the $20 \mu \mathrm{M}$ concentration of etoposide, viability decreased from $89.7 \%$ to $41.1 \%$, reaching an immune cytotoxicity value of $48.6 \%$. (B) Mean cell viability of etoposide-treated CMK cells represented as bars. Results are the average of six independent experiments. Each error bar indicates the standard deviation. (C) Increase in immune cytotoxicity in etoposide-treated CMK cells depicted in a box-andwhisker plot. The mean immune cytotoxicity rose 3.2-fold with the lower concentration and 3.7-fold with the higher concentration compared to baseline. 
apoptotic or dead cells. The cell solution was subsequently incubated for 20 minutes in the dark, at room temperature. To standardize the analysis, $10 \mu \mathrm{l}$ of Flow-count ${ }^{\mathrm{TM}}$ fluorospheres and $400 \mu \mathrm{l}$ of Annexin Buffer were added to cell suspensions at the end of the incubation. We utilized flow cytometry (EPICS-XL MCL, Coulter, Miami, FL), to assess in vitro cell-mediated cytotoxicity [36]. CD33-positive events were gated on, and analysis of ann $\mathrm{V}$ versus $\mathrm{PI}$ binding displayed the viable (annV/PI) and apoptotic/dead cells. Immune cytotoxicity of the control and drug-pretreated groups was defined as the loss of (percentage) viability following CTL-mediated immune attack on target cells, relative to baseline. This value was calculated as below:

Immune cytotoxicity = (baseline cell viability) (cell viability after co-incubation with CTLs)

Each experiment was repeated six times, on different days.

\section{Statistical Analysis}

One-way analysis of variance was used to compare immune cytotoxicity values between differing concentrations of drugs and controls for each drug experiment. Bonferroni correction was used to reduce type I error in deriving significance of these comparisons. Significance was determined as $\mathrm{p}$ : < 0.05 . All statistic calculations were performed using the Statistical Package for Social Sciences (SPSS-12.5 for Windows).

\section{RESULTS}

\section{Etoposide Pretreatment Enhanced CTL-Mediated Cytotoxicity in the CMK Cell Line}

Although CMK cells showed minimal susceptibility to CTL-mediated immune cytotoxicity at baseline, this susceptibility became more pronounced following pretreatment with etoposide, as shown in Figure 1. The mean cell viability dropped from $92.4 \pm 2.2 \%(95 \% \mathrm{Cl}$ $90.1-94.7)$ to $71.1 \pm 13.8 \%(95 \%$ Cl $56.6-85.6)$ $(p=0.002)$ following co-incubation with CTLs, in cells pretreated with the $2 \mu \mathrm{M}$ concentration of the drug. Although this signified a 3.2-fold increase in the mean immune cytotoxicity from the baseline value of $6.6 \pm$ $3.8 \%(95 \% \mathrm{Cl} 2.6-10.6)$ to $21.4 \pm 12.9 \%(95 \% \mathrm{Cl} 7.8$ - 34.9), statistical significance was not reached (p:0.09). In cells pretreated with the $20 \mu \mathrm{M}$ concentration of etoposide, the mean cell viability plummeted to $67.6 \pm 13.7 \%(95 \% \mathrm{Cl} 53.2-82.0)$ from a baseline value of $91.0 \pm 2.7 \%(95 \% \mathrm{Cl} 88.2-93.9)$ following co-incubation with CTLs $(p:<0.001)$, translating into a 3.7-fold increase in mean immune cytotoxicity to $23.4 \pm 12.6 \%(95 \% \mathrm{Cl} 10.2-36.7$, $\mathrm{p}:<0.05)$, compared to the baseline value.

\section{Cytarabine Pretreatment Enhanced CTL-Mediated Cytotoxicity in the CMK Cell Line}

CMK cells pretreated with cytarabine have also displayed a trend towards increased susceptibility to CTL-mediated immune attack (Figure 2); however, statistical significance was not reached. In CMK cells pretreated with the lower $(1 \mu \mathrm{M})$ concentration of cytarabine, the mean cell viability dropped from the baseline value of $95.0 \pm 2.0 \%(95 \% \mathrm{Cl} 92.8-97.1)$ to $80.7 \pm 13.1 \%(95 \% \mathrm{Cl} 66.9-94.5)$ (p: 0.265$)$. With this concentration, the mean immune cytotoxicity increased 1.6 -fold to $14.3 \pm 11.2 \%(95 \% \mathrm{Cl} 2.5-26.0)$ compared to the control value of $8.7 \pm 6.3 \%(95 \% \mathrm{Cl} 2.1-15.3$, $\mathrm{p}=1.00)$. Pretreatment with the higher $(10 \mu \mathrm{M})$ concentration of cytarabine led to a drop in cell viability from the baseline value of $93.1 \pm 2.9 \%(95 \% \mathrm{Cl} 90.0-$ $96.1)$ to $70.5 \pm 17.9 \%(95 \%$ Cl $51.7-89.2)(p=0.006)$. This signified a 2.6-fold increase in the mean immune cytotoxicity to $22.6 \pm 15.2 \%(95 \% \mathrm{Cl} 6.7-38.5$, $p=0.16$ ), compared to the baseline value given above.

\section{Pretreatment with Drugs did not Render K562 Cell Line More Susceptible to CTL-Mediated Immune Attack}

Unlike CMK cells, K562 cells showed resistance to both etoposide and cytarabine, and there was no increase in susceptibility to CTL-mediated immune attack. Baseline and co-incubation cell viability values were virtually unchanged in cytarabine-pretreated cells, yielding mean immune cytotoxicity values of $2.2 \pm 2.8 \%$ $(95 \% \mathrm{Cl}-0.7-5.1), 0.7 \pm 1.7 \%(95 \% \mathrm{Cl}-1.1-2.5)$, and $1.9 \pm 2.2 \%(95 \% \mathrm{Cl}-0.4-4.1)$, for baseline, lowerconcentration, and higher-concentration pretreatment groups, respectively. Etoposide pretreatment produced similar results, with little and insignificant change in mean immune cytotoxicity: $0.4 \pm 0.6 \%(95 \% \mathrm{Cl}-0.2-$ $1.0), 1.0 \pm 1.1 \%(95 \% \mathrm{Cl}-0.2-2.2)$, and $0.5 \pm 1.4 \%$ $(95 \% \mathrm{Cl} 1.0-2.0)$ for baseline, lower-concentration, and higher-concentration pretreatment groups, respectively.

\section{DISCUSSION}

In this study, we have demonstrated that antileukemic in vitro cytotoxicity mediated by stimulated CD8+ CTLs is enhanced by pretreatment of certain 


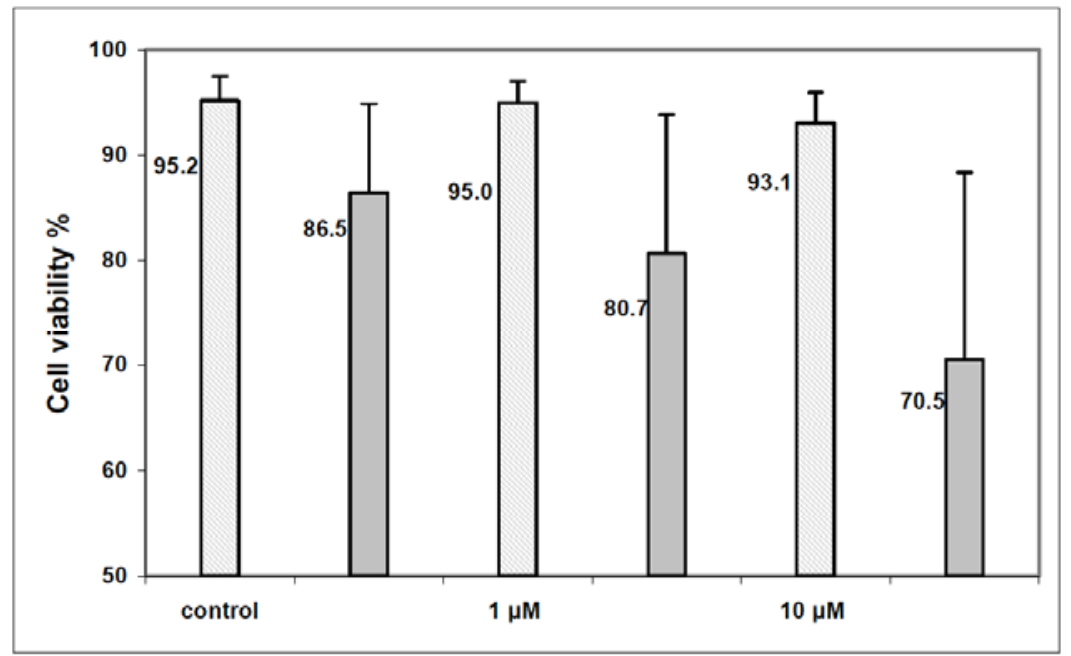

A

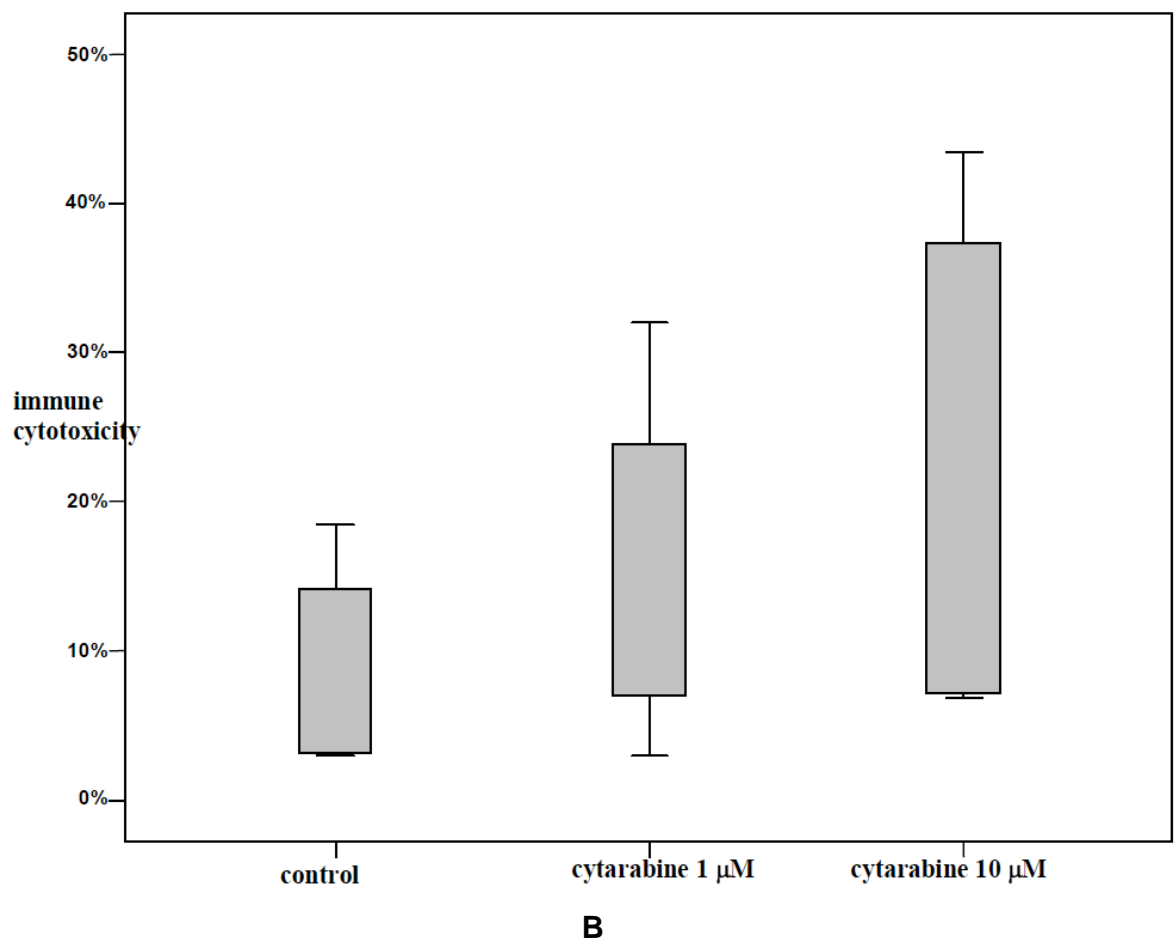

Figure 2: Pretreatment with cytarabine increases susceptibility of CMK cells to CTL-mediated cytotoxicity. (A) Mean cell viability of cytarabine-treated CMK cells represented as bars. Results are the average of six independent experiments. Each error bar indicates the standard deviation. (B) Increase in immune cytotoxicity in etoposide-treated CMK cells depicted in a box-andwhisker plot. The mean immune cytotoxicity rose 1.6-fold with the lower concentration and 2.6-fold with the higher concentration compared to baseline.

leukemia cells with chemotherapeutic drugs. This is in accordance with the previous studies that have demonstrated an increased LAK or CTL-mediated cytotoxicity in several tumor cell lines that were pretreated with chemotherapeutic drugs [13-30].

The effector cells used in the cytotoxicity assays were allogeneic unprimed CD8+ T cells. This is more representative of the clinical setting of allogeneic HSCT for acute myeloid leukemia, where donor's cells are not sensitized against the recipient's leukemic antigens.
NK cells exert a more efficient GVL reaction while avoiding graft-versus-host effects, and therefore constitute a promising tool for immune therapy of leukemia; however, their use is fraught with the necessity of finding NK alloreactive donors [37, 38]. For these two reasons, we chose to use unprimed CD8+ T cells, to mimic the clinical setting.

Activation of naïve $T$ cells was achieved with the use of $\mathrm{IL}-2$ and $\mathrm{IL}-15$, whereas the mitogen phytohemagglutinin-P aided in expanding the number 
of $T$ cells. Naïve CD8+ T cells can differentiate into CTLs when stimulated with IL-15, which not only stimulates synthesis of proinflammatory cytokines, interferon- $\gamma$ and TNF- $\alpha$, but also induces the expression of perforin and granzyme $B$ in these cells [39]. IL-15 can also induce bystander killing in memory phenotype CD8+ T cells [40], and these cells could have contributed to the baseline cytotoxicity observed in our experiments. Magnetic separation of CD8+CD3+ cells was delayed until the $6^{\text {th }}$ day to take advantage of a heterogeneous milieu of peripheral blood mononuclear cells, which would include the NK cells and the monocytes. The presence of monocytes enhances the LAK activity of T cells [41].

The CMK cell line was particularly sensitive to pretreatment with both chemotherapeutic drugs (etoposide and cytarabine). This cell line is known to be sensitive to chemotherapy, especially cytarabine, a pyrimidine analog that disrupts DNA synthesis [42]. Cytarabine can also mediate apoptosis by inhibiting nuclear transcription factor kappa B (NF-кB) [43]. Interestingly, cytarabine pretreatment did not show a statistically significant immune-enhancing effect in our study. Repeated experiments, using higher concentrations of cytarabine, should be executed to explore the presence of various immune-enhancing effect of this drug against the CMK cell line.

We did not observe an increased susceptibility to CTL-mediated killing in K562 cells following exposure to chemotherapeutic drugs. It is possible that there was an acquired resistance in the $\mathrm{K} 562$ cell line we used in our experiments, preventing not only drug-induced cytotoxicity but also induction of apoptosis [44]. It is possible that in the concentrations used in our experiments, the drugs were not able to affect the intracellular pathways of apoptosis in K562 cells. The molecular mechanisms that confer resistance to chemotherapy-induced apoptosis in leukemia cells must be explored in such resistant cells. Identifying such mechanisms may help explain why such cells are also resistant to immune-mediated cytotoxicity.

In conclusion, the results of our study suggest that pretreatment with chemotherapy (e.g. etoposide and cytarabine) and allogeneic cell-mediated immune therapy act in synergy against the CMK cell line. Further studies, that make use of different drugs and that involve multiple cell lines and possibly patient samples, are warranted to establish the presence of a synergy between chemotherapy and the anti-leukemic immune response. If the existence of such a phenomenon is proven to exist, its clinical applications may help achieve an improved cure rate in leukemia.

\section{REFERENCES}

[1] Kolb HJ, et al. Graft-versus-leukemia reactions in allogeneic chimeras. Blood 2004; 103(3): 767-76. http://dx.doi.org/10.1182/blood-2003-02-0342

[2] Shah NN, Dave H, Wayne AS. Immunotherapy for pediatric leukemia. Front Oncol 2013; 3: 166. http://dx.doi.org/10.3389/fonc.2013.00166

[3] Horowitz MM, et al. Graft-versus-leukemia reactions after bone marrow transplantation. Blood 1990; 75(3): 555-62.

[4] Drobyski WR, et al. Molecular remission occurring after donor leukocyte infusions for the treatment of relapsed chronic myelogenous leukemia after allogeneic bone marrow transplantation. Bone Marrow Transplant 1992; 10(3): 301-4.

[5] Chang YJ, Huang XJ. Donor lymphocyte infusions for relapse after allogeneic transplantation: when, if and for whom? Blood Rev 2013; 27(1): 55-62. http://dx.doi.org/10.1016/j.blre.2012.11.002

[6] Cheung NV, Rooney CM. Principles of immune and cellular therapy in Principles and Practice of Pediatric Oncology, P.A. Pizzo and D.G. Poplack, Editors. 2002, Lippincott Williams and Wilkins: Philadelphia. p. 381-408.

[7] Takei F. LAK cell therapy of AML: not to be lost in translation. Exp Hematol 2011; 39(11): 1045-6. http://dx.doi.org/10.1016/j.exphem.2011.08.005

[8] Russell JH, Ley TJ. Lymphocyte-mediated cytotoxicity. Annu Rev Immunol 2002; 20: 323-70.

http://dx.doi.org/10.1146/annurev.immunol.20.100201.131730

[9] Smyth MJ, et al. Nature's TRAIL-on a path to cancer immunotherapy. Immunity 2003; 18(1): 1-6. http://dx.doi.org/10.1016/S1074-7613(02)00502-2

[10] Stuckey DW, Shah K. TRAIL on trial: preclinical advances in cancer therapy. Trends Mol Med 2013; 19(11): 685-94. http://dx.doi.org/10.1016/j.molmed.2013.08.007

[11] Kelley SK, Ashkenazi A. Targeting death receptors in cancer with Apo2L/TRAIL. Curr Opin Pharmacol 2004; 4(4): 333-9. http://dx.doi.org/10.1016/j.coph.2004.02.006

[12] Srivastava RK. TRAIL/Apo-2L: mechanisms and clinical applications in cancer. Neoplasia 2001; 3(6): 535-46. http://dx.doi.org/10.1038/sj.neo.7900203

[13] Matsuzaki I, et al. Cisplatin induces fas expression in esophageal cancer cell lines and enhanced cytotoxicity in combination with LAK cells. Oncology 2000; 59(4): 336-43. http://dx.doi.org/10.1159/000012192

[14] Wang MJ, et al. [Chemotherapeutic drugs enhanced rsTRAIL tumoricidal activity]. Zhongguo Yi Xue Ke Xue Yuan Xue Bao 2004; 26(5): 524-8.

[15] Beranova L, et al. The plant alkaloid and anti-leukemia drug homoharringtonine sensitizes resistant human colorectal carcinoma cells to TRAIL-induced apoptosis via multiple mechanisms. Apoptosis 2013; 18(6): 739-50. http://dx.doi.org/10.1007/s10495-013-0823-9

[16] Iwase $\mathrm{M}$, et al. Enhanced susceptibility of oral squamous cell carcinoma cell lines to FAS-mediated apoptosis by cisplatin and 5-fluorouracil. Int J Cancer 2003; 106(4): 619-25. http://dx.doi.org/10.1002/ijc.11239

[17] Mishima K, Nariai Y, Yoshimura Y. Carboplatin induces Fas (APO-1/CD95)-dependent apoptosis of human tongue carcinoma cells: sensitization for apoptosis by upregulation of FADD expression. Int J Cancer 2003; 105(5): 593-600. http://dx.doi.org/10.1002/ijc.11133

[18] Mizutani $\mathrm{H}$, et al. Mechanism of apoptosis induced by doxorubicin through the generation of hydrogen peroxide. Life Sci 2005; 76(13): 1439-53. 


\section{http://dx.doi.org/10.1016/j.lfs.2004.05.040}

[19] Mizutani $Y$, et al. Enhanced susceptibility of cisdiamminedichloroplatinum-treated K562 cells to lysis by peripheral blood lymphocytes and lymphokine activated killer cells. Cancer 1993; 71(4): 1313-21.

http://dx.doi.org/10.1002/1097-

0142(19930215)71:4<1313::AID CNCR2820710424>3.0.CO;2-

[20] Mizutani $Y$, et al. Doxorubicin sensitizes human bladder carcinoma cells to Fas-mediated cytotoxicity. Cancer 1997; 79(6): 1180-9.

http://dx.doi.org/10.1002/(SICI)10970142(19970315)79:6<1180::AID-CNCR17>3.0.CO;2-W

[21] Mizutani Y, Yoshida O, Bonavida B. Sensitization of human bladder cancer cells to Fas-mediated cytotoxicity by cisdiamminedichloroplatinum (II). J Urol 1998; 160(2): 561-70. http://dx.doi.org/10.1016/S0022-5347(01)62959-8

[22] Posovszky $\mathrm{C}$, et al. Chemotherapeutic drugs sensitize pre-B ALL cells for CD95- and cytotoxic T-lymphocyte-mediated apoptosis. Leukemia 1999; 13(3): 400-9. http://dx.doi.org/10.1038/sj.leu.2401327

[23] Uslu $\mathrm{R}$, et al. Chemosensitization of human prostate carcinoma cell lines to anti-fas-mediated cytotoxicity and apoptosis. Clin Cancer Res 1997; 3(6): 963-72.

[24] Uslu R, Jewett A, Bonavida B. Sensitization of human ovarian tumor cells by subtoxic CDDP to anti-fas antibodymediated cytotoxicity and apoptosis. Gynecol Oncol 1996; 62(2): 282-91.

http://dx.doi.org/10.1006/gyno.1996.0228

[25] Wu XX, et al. Doxorubicin enhances TRAIL-induced apoptosis in prostate cancer. Int J Oncol 2002; 20(5): 94954 http://dx.doi.org/10.1002/ijc.10948

[26] Wu XX, et al. Enhancement of TRAIL/Apo2L-mediated apoptosis by adriamycin through inducing DR4 and DR5 in renal cell carcinoma cells. Int J Cancer 2003; 104(4): 409-17.

[27] Wu XX, et al. Enhancement of Fas-mediated apoptosis in renal cell carcinoma cells by adriamycin. Cancer Res 2000; 60(11): 2912-8.

[28] Yamamoto $T$, et al. Enhanced apoptosis of squamous cell carcinoma cells by interleukin-2-activated cytotoxic lymphocytes combined with radiation and anticancer drugs. Eur J Cancer 2000; 36(15): 2007-17. http://dx.doi.org/10.1016/S0959-8049(00)00244-6

[29] Yamaue $\mathrm{H}$, et al. Cisplatin treatment renders tumor cells more susceptible to attack by lymphokine-activated killer cells. J Clin Lab Immunol 1991; 35(4): 165-70.

[30] Johnston JB, et al. Role of the TRAIL/APO2-L death receptors in chlorambucil- and fludarabine-induced apoptosis in chronic lymphocytic leukemia. Oncogene 2003; 22(51): 8356-69.

http://dx.doi.org/10.1038/sj.onc. 1207004

[31] Jones DT, et al. Cytotoxic drugs enhance the ex vivo sensitivity of malignant cells from a subset of acute myeloid leukaemia patients to apoptosis induction by tumour necrosis factor receptor-related apoptosis-inducing ligand. $\mathrm{Br} J$ Haematol 2003; 121(5): 713-20.

http://dx.doi.org/10.1046/j.1365-2141.2003.04340.x
[32] Ozdemir O, Savasan S. Combinational IL-2/IL-15 induction does not further enhance IL-15-induced lymphokineactivated killer cell cytotoxicity against human leukemia/lymphoma cells. Clin Immunol 2005; 115(3): 240-9. http://dx.doi.org/10.1016/j.clim.2005.01.008

[33] Savasan S, et al. Evaluation of cytotoxicity by flow cytometric drug sensitivity assay in childhood T-cell acute lymphoblastic leukemia. Leuk Lymphoma 2005; 46(6): 833-41. http://dx.doi.org/10.1080/10428190500079951

[34] Lozzio BB, Lozzio CB. Properties of the K562 cell line derived from a patient with chronic myeloid leukemia. Int $\mathrm{J}$ Cancer 1977; 19(1): 136. http://dx.doi.org/10.1002/ijc.2910190119

[35] Sato T, et al. Establishment of a human leukaemic cell line (CMK) with megakaryocytic characteristics from a Down's syndrome patient with acute megakaryoblastic leukaemia. $\mathrm{Br}$ J Haematol 1989; 72(2): 184-90. http://dx.doi.org/10.1111/j.1365-2141.1989.tb07681.x

[36] Ozdemir O, Ravindranath Y, Savasan S, Cell-mediated cytotoxicity evaluation using monoclonal antibody staining for target or effector cells with annexinV/propidium iodide colabeling by fluorosphere-adjusted counts on three-color flow cytometry. Cytometry A 2003; 56(1): 53-60. http://dx.doi.org/10.1002/cyto.a.10081

[37] Ruggeri L, et al. Natural killer cell alloreactivity in haploidentical hematopoietic stem cell transplantation. Int $J$ Hematol 2005; 81(1): 13-7. http://dx.doi.org/10.1532/IJH97.04172

[38] Locatelli F, et al. Cellular and molecular basis of haploidentical hematopoietic stem cell transplantation in the successful treatment of high-risk leukemias: role of alloreactive NK cells. Front Immunol 2013; 4: 15. http://dx.doi.org/10.3389/fimmu.2013.00015

[39] Alves NL, et al. IL-15 induces antigen-independent expansion and differentiation of human naive CD8+ T cells in vitro. Blood 2003; 102(7): 2541-6. http://dx.doi.org/10.1182/blood-2003-01-0183

[40] Weng NP, et al. IL-15 is a growth factor and an activator of CD8 memory T cells. Ann N Y Acad Sci 2002; 975: 46-56. http://dx.doi.org/10.1111/j.1749-6632.2002.tb05940.x

[41] Sone, S, et al. Heterogeneity of human lymphokine (IL-2)activated killer (LAK) precursors and regulation of their LAK induction by blood monocytes. Int J Cancer 1988; 42(3): 42834.

http://dx.doi.org/10.1002/ijc.2910420320

[42] Taub JW, et al. Expression of chromosome 21-localized genes in acute myeloid leukemia: differences between Down syndrome and non-Down syndrome blast cells and relationship to in vitro sensitivity to cytosine arabinoside and daunorubicin. Blood 1999; 94(4): 1393-400.

[43] Sreenivasan Y, Sarkar A, Manna SK. Mechanism of cytosine arabinoside-mediated apoptosis: role of Rel A (p65) dephosphorylation. Oncogene 2003; 22(28): 4356-69. http://dx.doi.org/10.1038/sj.onc.1206486

[44] Dimery IW, et al. Variation amongst K562 cell cultures. Exp Hematol 1983; 11(7): 601-10. 